\title{
Mountainous Forest Brown Soils Humus of Republic of Armenia
}

\author{
Kroyan Samvel, Ghazaryan Hunan \\ National Agrarian University of Armenia, Scientific Center of Soil Sciences, Agrochemistry and Melioration After H. P. Petrosyan, \\ Yerevan, Republic of Armenia
}

Email address:

kroyan.samvel@mail.ru (K. Samvel), ghazaryan_soil@yahoo.com (G. Hunan)

\section{To cite this article:}

Kroyan Samvel, Ghazaryan Hunan. Mountainous Forest Brown Soils Humus of Republic of Armenia. American Journal of Agriculture and Forestry. Vol. 6, No. 1, 2018, pp. 1-7. doi: 10.11648/j.ajaf.20180601.11

Received: December 11, 2017; Accepted: December 24, 2017; Published: January 11, 2018

\begin{abstract}
The humus of Republic of Armenia forest brown soils has been studied. It turned out that these soils are characterized by high content of humus; up to $11,2 \%$, which gradually decreases parallel with the soil profile depth. The humus content in plant litter reaches up to the $21,8 \%$. One of the most important features in the forest brown soils is a high hydrolysis character of humus. The total balance of carbon of humus substances is $17.0-43.6 \%$, which shows the weak linkage of humus with the mineral part of the soil. In general the presence of black HA in the content of humin acids is not typical for forest brown soils. It is well known that in forest grey soil prevail FA and grey FA and the absence of HA, which are combined with exchanging $\mathrm{Ca}$, moving $\mathrm{R}_{2} \mathrm{O}_{3}$ - as well as with the acid reaction of the soil, which consider being main connectors of humic substances.
\end{abstract}

Keywords: Humus, Humin Acids, Fulvic Acids, Non-Hydrolytically Residue, Optical Density

\section{Introduction}

In the modern era of climate global change, one of the primary issues facing the society is the effective use of land resources, their improvement and preservation.

For our scarce-soil republic thorough investigations of soil humus fund has a great importance. Clarification of these and other similar issues are of particular importance especially for mountainous forest grey soils of the country.

One of the most urgent issues in the territory of the Republic of Armenia is research on mitigation of negative phenomena caused on the soil by climate changes and anthropogenic impacts. Despite the fact that changes in the soil due to climate changes and anthropogenic effects are very different, one of the important factors contributing to the degradation of the forest grey soil is the reduction of the total content of humus and the stockpile, which negatively affects the fertility of soil and crop yields. From the results of the research, it becomes clear that humus content in these lands is generally quite high, but anyhow a certain decrease in humus and humin substances is observed in the sub-species.

In order to improve the humus of the forest brown soils, increase fertility, effective use and conservation of lands, it is necessary to develop and implement a comprehensive scientifically justified agro-technical system.

\section{The Material, Object and Method}

As a research material served changes in humus and humin substances in the forest brown soils of the Republic of Armenia, which occur because of economic reasons, unreasonable activities and climate global change.

The object of the research was the forest brown soils of the republic. The research has been carried out by the method of comparing weak unsaturated and strong unsaturated soil subtypes of forest brown soils.

Fieldworks had been carried out by the method of soil field extraction and the laboratory researches by modern methods of soil-science [1].

The humus content of the soil was determined by Tyurin method and the humus group composition by the methods of Kononova and Belchikova [2, 3].

\section{Discussion of Results}

The Republic of Armenia is a typically mountainous 
country with poor soil resources. Depending on the difference of the surfaces of high dimensional levels, the entire complex of soil-formatting factors is changing in the territory of the republic, conditioning the upward zoning distribution of soils. In the unique physico-geographical conditions of each upward zonality various genetic types, subtypes, genes, species have been developed by their own origin, composition, structure and agro-industrial characteristics, which follow each other from lower places to the high mountain peaks [4]. According to the upward zonality the forest brown soils occupy the northeastern part of the republic; the mountain slopes of $1300-2250 \mathrm{~m}$ above sea level. The criteria presented in the World Reference Base for Soil Resources (WRB) have been adopted as the classification criteria for all genetic soil-types and subtypes of the Republic. According to this classification, the brown soils of the forest correspond to the name Cambisols [5, 6]. In the territory of the Republic of Armenia the forest brown soils were formed under beech and hornbeam forests, where besides these there are also highland maple, common ash
(Fraxinus excelsior), highland elm, and from the bushes junipers, Sambucus, hawthorn, etc. In the area of these soils Coniferous trees meet rarely.

In the well-lit areas of the forest, grass vegetation is well developed, where dominate Salvia, Mentha (mint), Campanula, sweetbrier, etc. [7].

The efficient plant coverage of the forest is 338-612 c/ha, including the surface area of $155 \mathrm{c} / \mathrm{ha}$, and the roots of 182$457 \mathrm{c} / \mathrm{ha}$. The amount of vegetable splinter varies in $42-99 \mathrm{c}$ / ha and makes $10-23 \%$ of the vegetable mass. The accumulation of vegetable mass is being realized in sufficient acidic and non-carbonate profile [8]

The humus content in the republic forest brown soils varies widely from 2.8 to $11.2 \%$ (Figure $1,2,5,6$ ). The highest content of humus is noticeable in the forest lands close to Alpian zone of Lori region. The minimum content of humus is noticeable in weak saturated subtype soil near the town of Vanadzor. In the upper horizons of the above mentioned lands, parallel with the content of humus, the nitrogen content also changes and varies in the frames of $0.16-0.53 \%$.

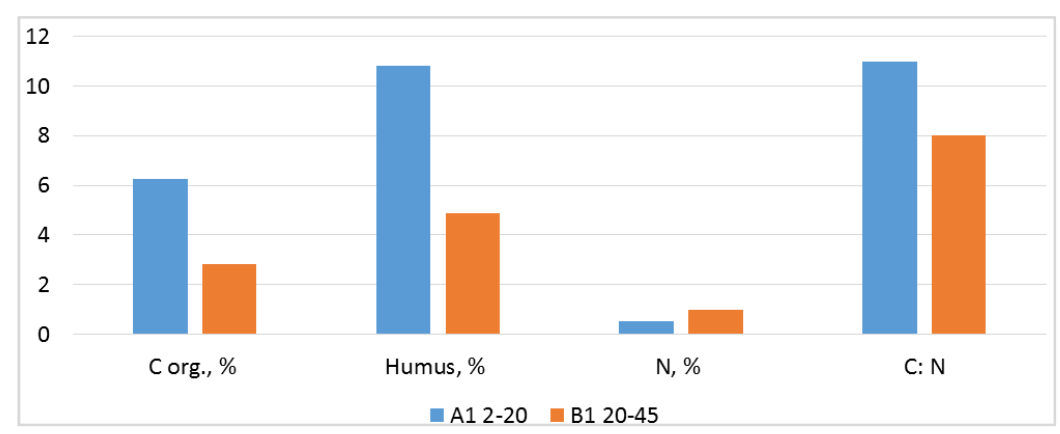

Figure 1. The humus of the forest brown slightly unsaturated soils, (\%).

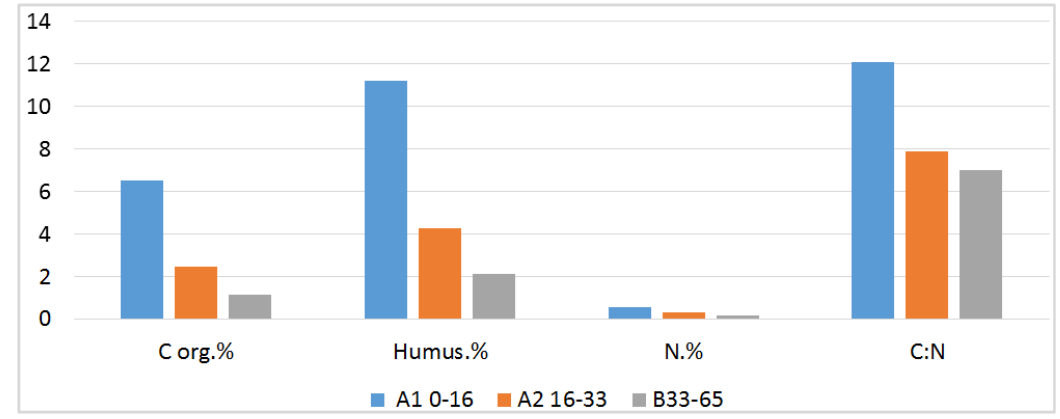

Figure 2. The humus content of the forest brown slightly unsaturated soils, (\%).

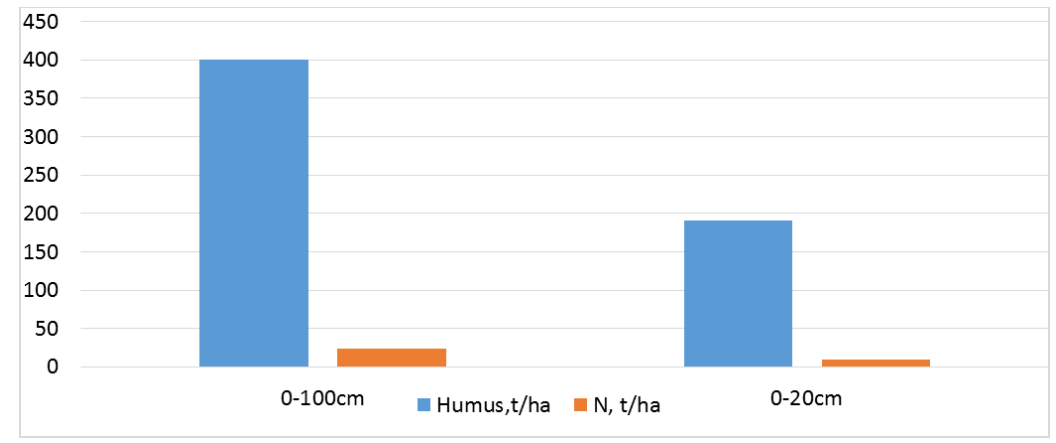

Figure 3. The humus and nitrogen reserves of forest brown slightly unsaturated soils ( $t$ /ha). 


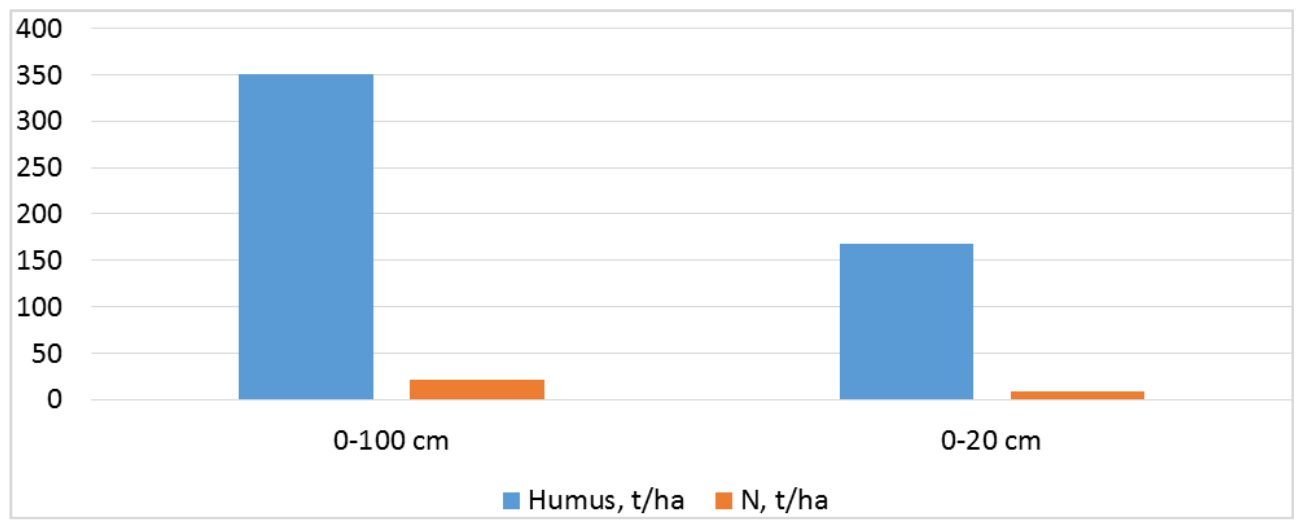

Figure 4. The humus and nitrogen reserves of forest brown slightly unsaturated soils ( $t / h a)$.

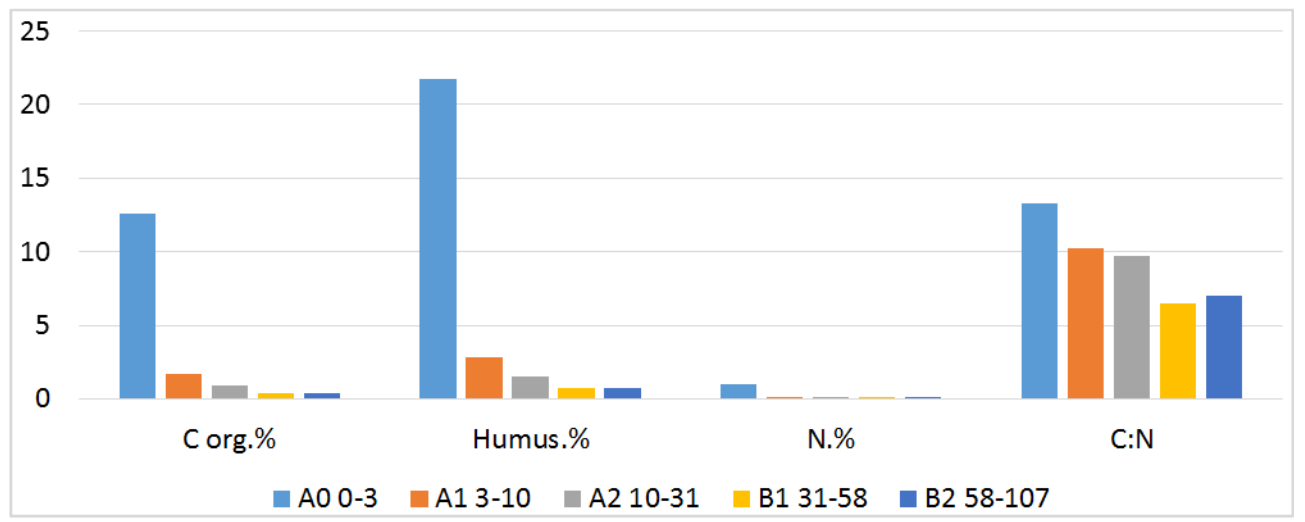

Figure 5. The humus content of forest brown silly-unsaturated soils (\%).

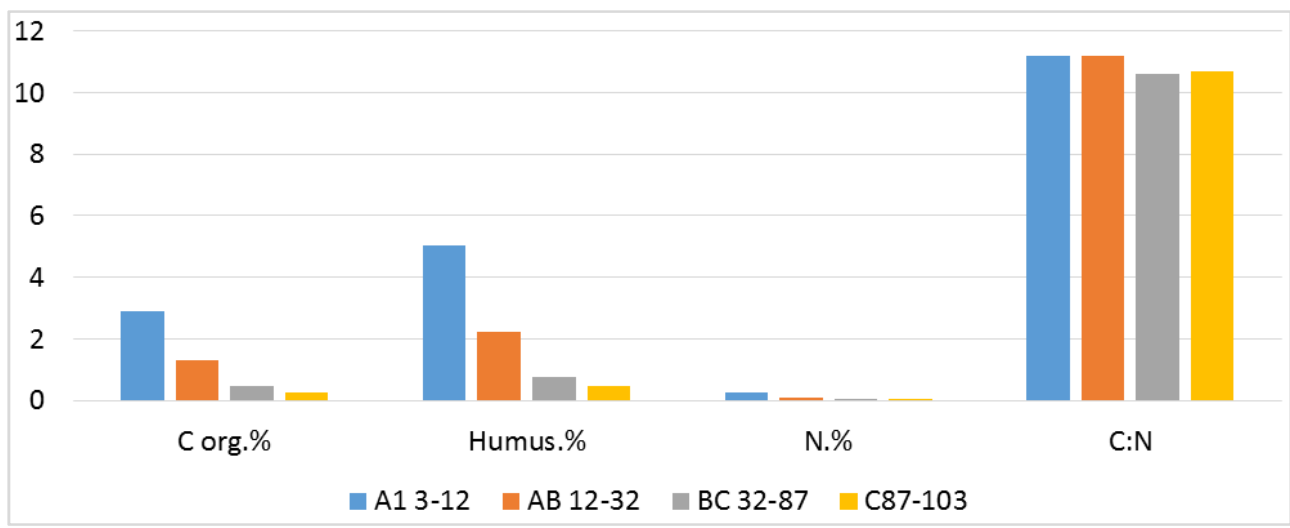

Figure 6. The humus content of forest brown silly-unsaturated soils (\%).

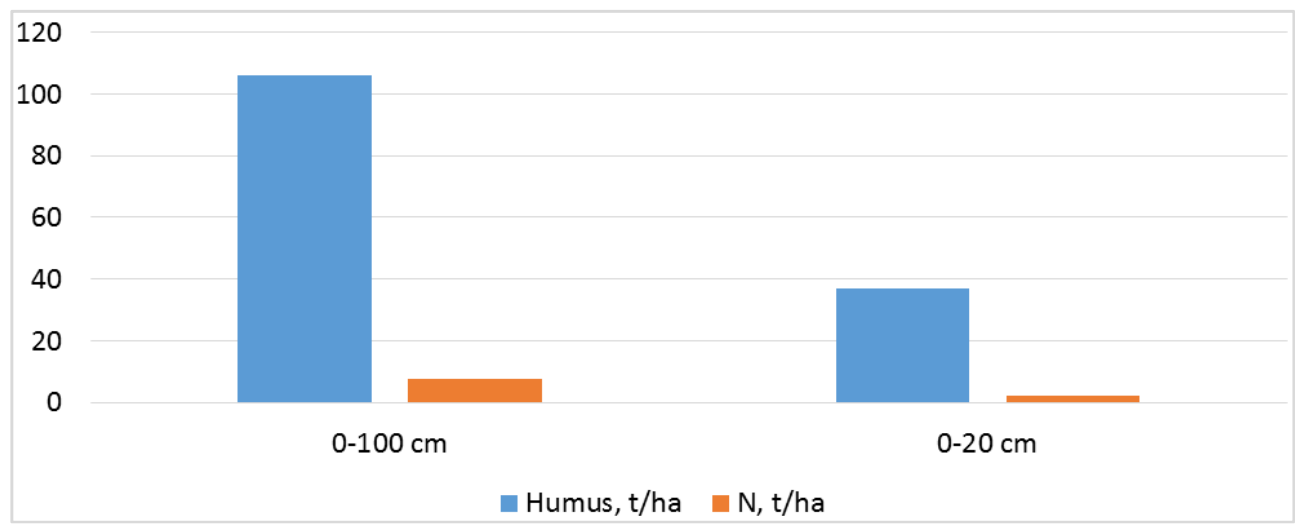

Figure 7. The humus and nitrogen reserves of forest brown silly-unsaturated soils (t/ha). 


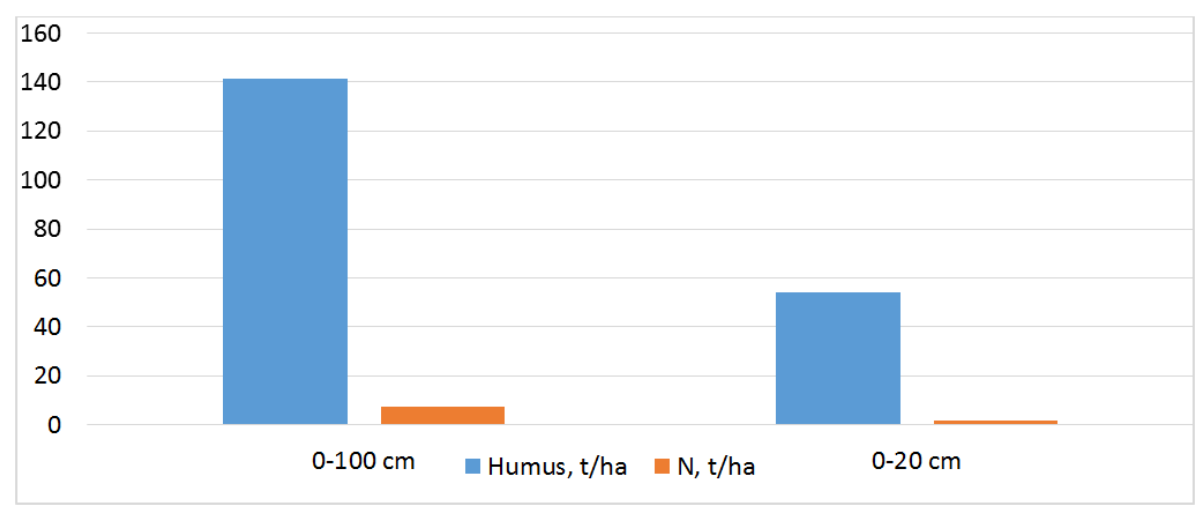

Figure 8. The humus and nitrogen reserves of forest brown silly-unsaturated soils (t/ha).

In upper humus cumulating layers of the soil the ratio $\mathrm{C}: \mathrm{N}$ varies widely, it forms 7.0-11.9 [9, 10] (Figure 1, 2, 5, 6).

As in all other soils of the republic, in the forest brown soils the upper horizons of the soil are distinguished by the highest content of humus, especially the 10-20 cm deep layer of soil, including the plant litter humus with its high humus content, where it reaches $21.8 \%$. Humus content in $30-40 \mathrm{~cm}$ layers of these lands sharply decreases, and in deeper layers, especially at depths of $60-70 \mathrm{~cm}$, it decreases gradually. Humus content in the upper horizons of soil is correlated with the total stock of humus in $1 \mathrm{~m}$ of soil.

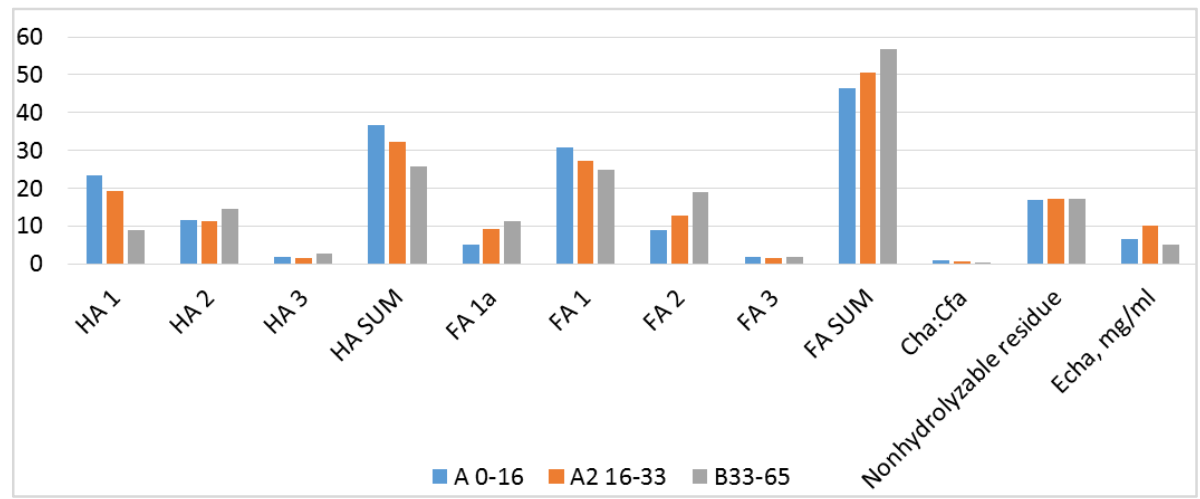

Figure 9. Humus composition of forest brown slightly unsaturated soils (C, \% of total organic carbon).

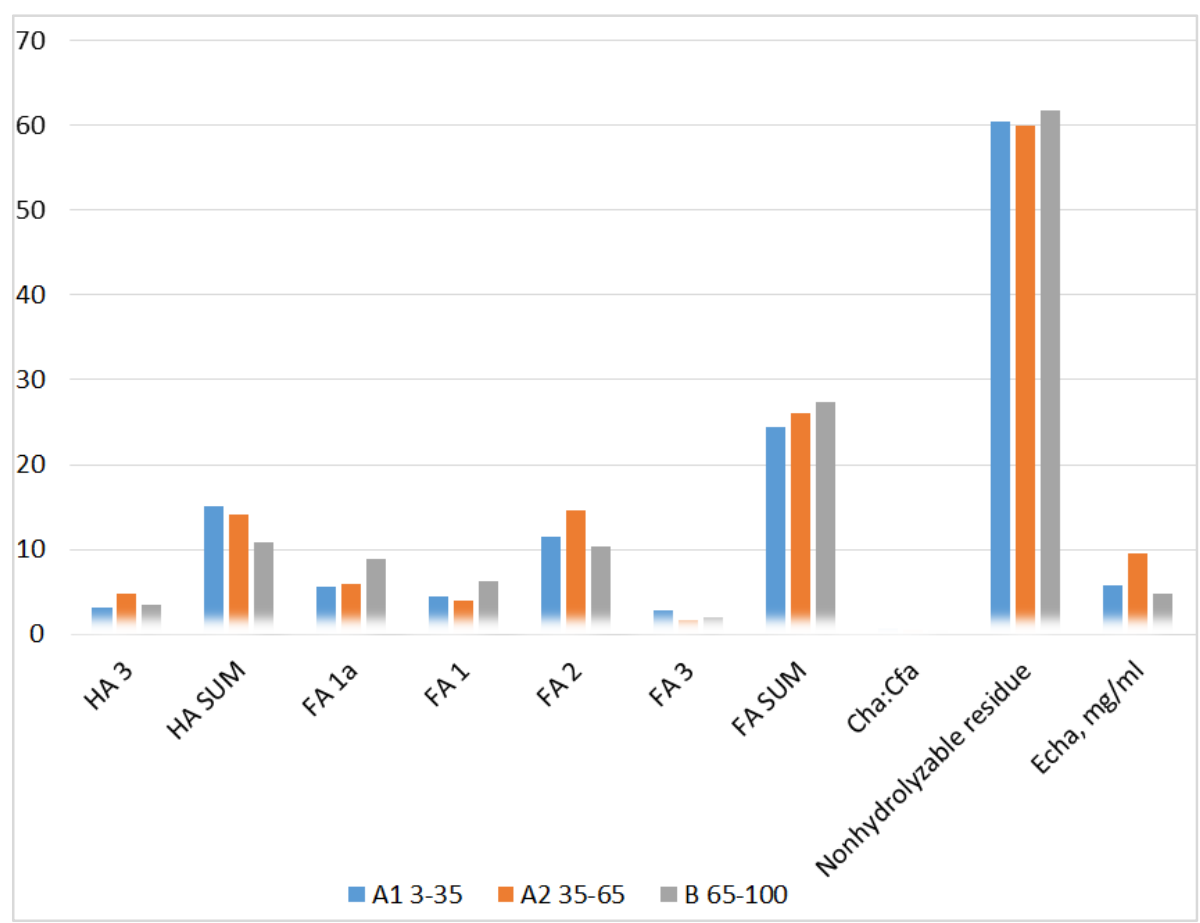

Figure 10. Humus composition of forest brown slightly unsaturated soils (C, \% of total organic carbon). 


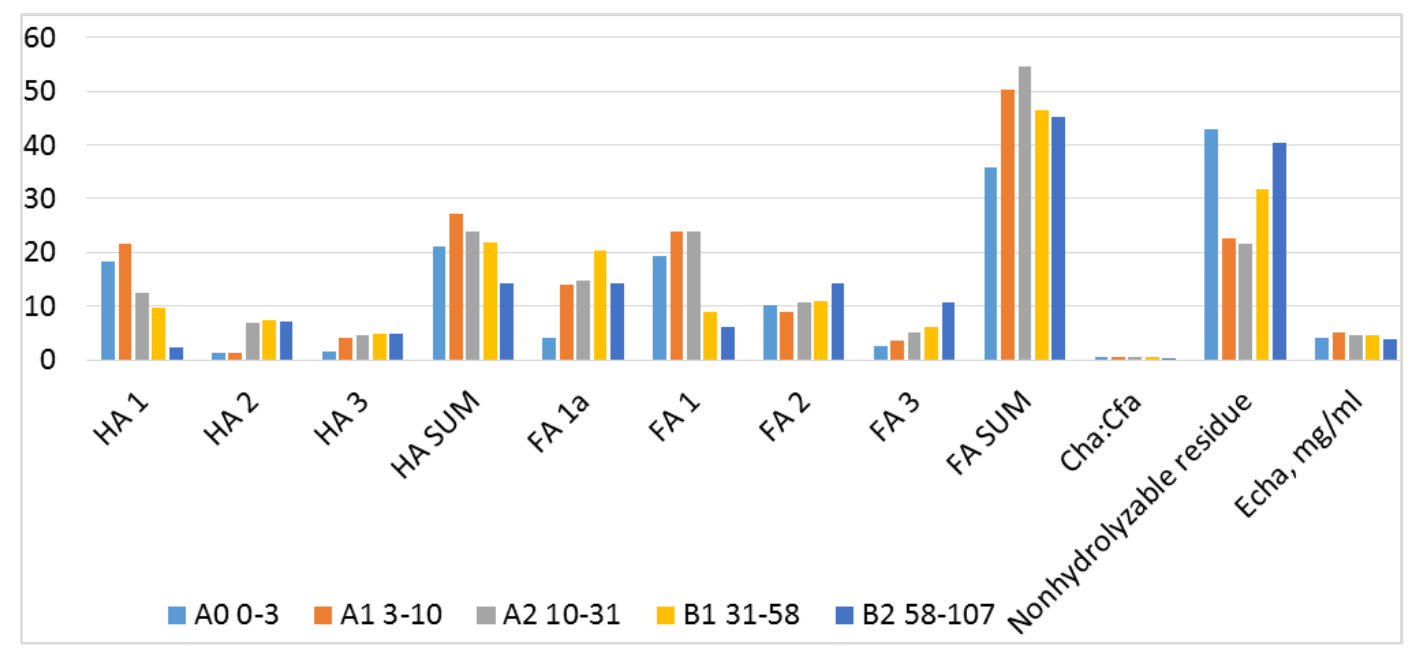

Figure 11. The composition of the humus content of forest brown silly-unsaturated soils (C, \% of total organic carbon).

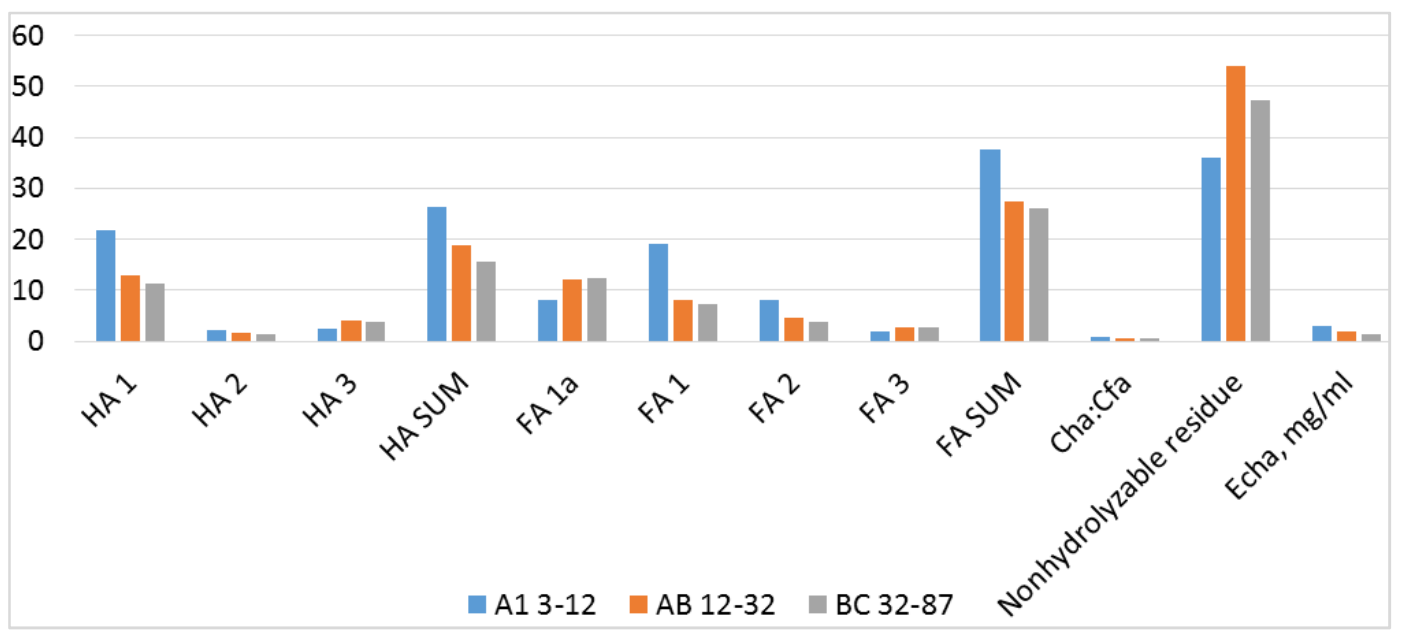

Figure 12. The composition of the humus content of forest brown silly-unsaturated soils (C, \% of total organic carbon).

As far as the potential and energetic fertility of the soil is determined by high content of humus, so the high indices of total humus reserves are also important like the percentage content of humus is important [11]. The total amount of humus in the 1 meter layer of soil is $160.0400 .0 \mathrm{t} / \mathrm{ha}$, and the total nitrogen reserves are 7.5-23.4 $\mathrm{t} /$ ha (Figure 3, 4, 7, 8 ). By the way $1 / 5$ of humus and nitrogen resources, in some cases, also $1 / 2$ of them are concentrated in the upper layer of the soil 0-20 cm [12, 13].

Processes of humus formation in weak as well as strong unsaturated subtypes of forest grey soils are realized by dominance of fulvic acids (FA) over humin acids (HA). The content of humin acids varies widely in the frames of 15$37 \%$, and the content of fulvic acids in the frames of $24-50 \%$ in the whole profile of the soil, especially in humus cumulative horizons. Parallel with the soil profile depth the content of humin acids decreases, and the content of fulvic acids increases. Cha: Cfa ratio in weak unsaturated subtypes of soil total profile varies from $0.83-0.40$, and in strong unsaturated sub-types of soil from 0,70 up to 0,32 (Figure 9, 10). Cha: Cfa ratio is quite wide especially in those subtypes of weak unsaturated soil, which have been formed on the maternal rocks of carbonate origin [14].
The dominance of fulvic acids over humin acids in forest grey soils conditioned the presence of humin-fulvic (Cha: $\mathrm{Cfa}<1)$ type humus in upper horizons and the presence of fulvic (Cha: $\mathrm{Cfa}<0,5)$ type in lower horizons.

One of the most important features in the forest brown soils is a high hydrolysis character of humus. The total balance of carbon of humus substances is $17.0-43.6 \%$, which shows the weak linkage of humus with the mineral part of the soil (Figure 9, 11, 12).

In the fractional content of humin acids, in weak unsaturated as well as strong unsaturated subtypes soils, prevails HA-1 fraction). However, they can not be migrated in the soil profile because of their water non- solubility properties and are mostly accumulated in humus horizons.

The content of HA-2 that is connected with the $\mathrm{Ca}$ considerably increases out of the border of humus horizons [15].

In the forest grey soils of RA there is an increase of black HA-2 share in the group of HA from strong unsaturated soils to the weak unsaturated soils. This phenomenon is noticeable especially in those soils, which are formed on carbon rocks, where the HA-2 fraction in the whole profile of the soils prevails over grey HA-2 fraction. 
In general the presence of black HA in the content of humin acids is not typical for forest brown soils. It is well known that in forest grey soil prevail FA and grey FA and the absence of $\mathrm{HA}$, which are combined with exchanging $\mathrm{Ca}$, moving $\mathrm{R}_{2} \mathrm{O}_{3}$ - as well as with the acid reaction of the soil, which consider being main connectors of humic substances [16]. To the most characteristic features of forest brown soils the closest is the strong unsaturated subtype humus, where the narrowest is the Cha: Cfa ratio, and in the content of solid acids the part of grey HA is $73-83 \%$.

HA-3 solid bonded fraction of humin acids, as a rule is the least. It follows from this that HA of forest brown soils, especially of strong unsaturated subtypes' soils belong to the $\mathrm{HA}$ of very low optical density, where the $\mathrm{E}_{\mathrm{c}}=3.1-3.6$ $\mathrm{mg} / \mathrm{ml}$, which is characteristic to the HA color specifications and shows the low molecular weight condensation of the molecules. Exceptions are the soils formed on carbonate rocks, where the optical density of HA in B horizons is 10,5, which is largely due to the presence of quite high optical density HA-2 in the content of the humus (Figure 11, 12).

In the whole profile of forest brown soils in the fractional content of the FA prevail 1 a and 1 fractions.

In the content of plant litter organic substances dominate humines ( $43 \%$ of total $\mathrm{C}$, and $36 \%$ of $\mathrm{FA}$ ), and Cha: Cfa ratio is $0.6,[17,18]$.

Thus, the forest brown soils are characterized by sufficient or high content of organic substances, which gradually decreases along with the profile depth. Fulvic acids and grey humic acids prevail in the content of humic acids. In low horizons they are with the considerable amount of humin acids and low optical concentration of humin acids.

The difference of the content and characteristics of forest brown soils' is that in strong unsaturated subtype soils the ratio Cha: $\mathrm{Cfa}$ is quite narrow, in the content of humin acids prevail grey humic acids and humic acids have a low optical density.

\section{Conclusions}

1. The accumulation of plant mass is realized in enough acidic and non-carbonate profile of the soil.

2. The humus content in forest brown soils varies in wide ranges from 2.8 to $11.2 \%$.

3. In high humus accumulative horizons of soils the ratio $\mathrm{C}$ : $\mathrm{N}$ varies in wide range; $7,1-9,1$.

4. The humus content in plant litter reaches to $21,8 \%$.

5. The highest content of humus is found in the upper horizons of the soil, especially the $10-20 \mathrm{~cm}$ deep layer.

6. Fulvic acids (FA) dominate over humin acids (HA) both in weak and strong unsaturated subtypes of forest brown soils.

7. The ratio Cha: $\mathrm{Cfa}$ in the whole profile of the soil varies from 0,83 up to the 0,82 .

8. The dominance of fulvic acids over humic acids in forest brown soils conditioned the presence of humin-fulvic (Cha: $\mathrm{Cfa}<1)$ type humus in upper horizons and the presence of fulvic (Cha: $\mathrm{Cfa}<0,5)$ type in lower horizons.
9. In the forest brown soils there is an increase of black HA-2 share in the group of HA from strong unsaturated soils to the weak unsaturated soils.

\section{Annotation}

The humus of Republic of Armenia forest brown soils has been studied. It turned out that these soils are characterized by high content of humus; up to $11,2 \%$, which gradually decreases parallel with the soil profile depth. The humus content in plant litter reaches up to the $21,8 \%$.

One of the most important features in the forest brown soils is a high hydrolysis character of humus. The total balance of carbon of humus substances is $17.0-43.6 \%$, which shows the weak linkage of humus with the mineral part of the soil.

In general the presence of black HA in the content of humin acids is not typical for forest brown soils. It is well known that in forest grey soil prevail FA and grey FA and the absence of $\mathrm{HA}$, which are combined with exchanging $\mathrm{Ca}$, moving $\mathrm{R}_{2} \mathrm{O}_{3^{-}}$as well as with the acid reaction of the soil, which consider being main connectors of humic substances.

Fulvic acids and brown humic acids prevail in the content of humic acids. The soils are characterized with considerable amount of black humic acids and low optical density of humic acids in the low horizons. There are subtypes differences in the content and features of forest brown soils, which is due to the narrow ratio of Cha: Cfa in strong unsaturated subtype soils. Grey humic acids prevail in the content of humic acids, and the humic acids have low optical density.

\section{References}

[1] Nosin V. A. Petrov B. F.: "Methods and techniques of soil mapping": In the book of "Soil mapping" P. H. A. S. USSR, M. 1959, page 46-103.

[2] Arenushkina E. V. Guide on Soils Chemical Analysis. M., 1962, p. 475.

[3] Aleksandrov L. N., Naydenova O. A.- "Laboratory and practical classes on soil science". Leningrad, "Agropromizdat". - Leningrad Department, 1986. - pp. 109111 .

[4] K. G. Melqonyan, H. Gh. Ghazaryan, R. R. Manukyan "The environmental current situation of soils of agricultural importance", the level of the use of land, the improvement of management system and the ways of increasing effectiveness in the Republic of Armenia. Yerevan. 2004, page 53, (in Armenian).

[5] The world correlative base of soil resources: the basis for the international classification and correlation of soils. Compilers and scientific editors Targulyan V. O., Gerasimova M. I. Partnership of Scientific Publications KMC. Moscow 2007. 280 pages. (in Russian).

[6] World reference base for soil resourses. A framework for international classification, correlation and communication, World Soil Resources Report 103. Rome: FAO; 2006. (in English). 
[7] Tatevosyan G. S. "Mountainous Grey Soils of Murguz Ridge", Inst. of Soil Science and Agrochemistry, MA of Soviet Armenia, Issue 2, Yerevan 1963, P. 47-63.

[8] The soils of the Armenian SSR, under the editorship of P. A. Edilyan and others. P. H. Hayastan, Yerevan, 1976, p. 383.

[9] Badalyan E. N., Edilyan R. A., Characterization of the Nature and Properties of Humic acids in soils, Sov. Arm., Inst. of Soil Science and Agrochemistry, iss. 2, Yerevan 1976, P. 45-58.

[10] Badalyan E. N., Edilyan R. A., Comparative characteristics of organic substance of the main soil types of Sov. Arm.// journal Biologist, Armenia №7, 1979. - P. 695-703.

[11] Grishina L. A., Orlova D. S. System of Indices of Soils Humus State. In the book: Theses of Reports of the $\mathrm{V}$ Delegate Congress of the All-Union Community of Soil Scientists, edition 2, Minsk, 1978, pp. 3-7.

[12] Abdulahh Saparov, Chen Shi Czilili Abuduvayli; Soils of the Arid zone of Kazakhstan: Current state and their use. Almaty, 2014, p. 438.

[13] T. Urushadzea, W. Blumb, T. Kvrivishvilia Classification of soils on sediments, sedimentary and andesitic rocks in Georgia by the WRB system Annals of Agrarian Science Volume 14, Issue 4, December 2016, Pages 351-355. (in English).

[14] Dergacheva M. I., Nekrasova O. A., Lavrik N. L. Humin Acids in the Current Soils of Southern Ural, Preprint. Novosibirsk, 2002, p. 24.

[15] Dergachova M. I., Ryabova N., N.; Correlative Relations of Humus Composition and Climatic Indices in Conditions of Mountainous Areas of Southern Siberia // Newslatter of Tomsk Sate Univesrsity, 2005-№15. - P. 68-71.

[16] Kononova M. M. Determination of Common Content of Organic Carbon in Soils and Solutions by the Method of I. V. Tyurin. In the book: Organic Substance of Soil, its Nature, Features and Methods of Investigation, M., 1963, pp. 213-234.

[17] Trav nikova T. S. Regularities of Humus Accumulation: New Data and their Interpretation // Soil Science, 2002, № 7, pp. 832-843.

[18] Ponomareva V. V., Plotnikova T. A. Humus and soil formation. Ed. $<<$ Science $>>$.- L., 1980. -221 p. 